\title{
Study of ambulatory blood pressure in diabetic children: prediction of early renal insult
}

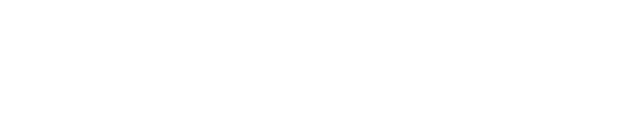

\author{
Nehad Mohamed Shalaby' \\ Naglaa M Shalaby ${ }^{2}$ \\ 'Pediatric Department, Faculty \\ of Medicine, Mansoura University, \\ Mansoura, Egypt; ${ }^{2}$ Department of \\ Medical Laboratory Technology, \\ Faculty of Applied Medical Sciences, \\ King Abdulaziz University, Jeddah, \\ Saudi Arabia
}

Background: Hypertension is a highly prevalent risk factor for cardiovascular disease in patients with type 1 diabetes mellitus. Elevated blood pressure (BP) promotes the development and progression of microvascular complications, eg, nephropathy and retinopathy. The purpose of this study was to identify and detect early BP changes in diabetic children and adolescents, aiming for the early prediction of future renal and cardiovascular disease risk during childhood.

Methods and materials: Ambulatory BP monitoring was undertaken for 40 normotensive type 1 diabetic children with mean age of $11.56 \pm 2.82$ years, and 24 healthy children as control group with matched age and sex. Albumin/creatinine ratio and glycated hemoglobin were tested. BP indices and standard deviation scores were calculated using reference standards. The data were analyzed by SPSS software version 20 using mean and standard deviations for descriptive data. Correlation and regression analysis tests were used to study relations between BP indices and diabetic parameters.

Results: All parameters of BP $z$-scores were highly significantly increased in diabetic patients compared with controlled group $(P<0.0001)$. The frequency of non-dipping was greater and highly significant in microalbuminuric diabetic patients $(P<0.0001)$. Regression analysis revealed that BP parameters were significantly related to albumin/creatinine ratio, glycated hemoglobin, insulin dose, and body mass index.

Conclusion: Our observation revealed a clear link between the nocturnal BP and microalbuminuria which mandates BP follow-up via ambulatory BP monitoring with therapeutic intervention to prevent renal and cardiovascular diabetic complications in adulthood.

Keywords: ambulatory, blood pressure, diabetic, children, renal

\section{Background}

Progression of microvascular complications in type 1 diabetic patients is influenced by arterial hypertension which is a well-recognized risk factor. ${ }^{1}$ Type 1 diabetes mellitus (T1DM) is associated with an excess of cardiovascular disease; patients with diabetic nephropathy have a higher risk than those diabetic patients without kidney involvement. $^{2}$

The diagnosis of hypertension is not an easy task, as one should follow measurement guidelines to decrease any avoidable mistakes thus giving accurate blood pressure (BP) readings. ${ }^{3}$ In adults, to diagnose hypertension, measurements should be above the known normal levels. In children and adolescents, the task is more difficult as one should follow the percentile levels of BP of each age. Persistent readings of more than 95th percentile is considered hypertension in this age group. ${ }^{4}$

In patients with T1DM, especially the pediatric group, sporadic clinic BP measurement is not reliable. Measuring of BP over an extended period of time is more convenient and thus a highly valuable and effective tool. ${ }^{5}$ Many studies have now confirmed that BP measured over a 24-hour period is superior to clinic BP measurement
Shalaby

Pediatric Department, Faculty of

Medicine, Mansoura University

Children's Hospital, Mansoura University,

Algomhoriyah Street, Mansoura 35516,

Egypt

Tel +2050231 9621

Email amahalawy2002@yahoo.com
Therapeutics and Clinical Risk Management 20 I5:I I I53 I-I537

| 53 |

Dovepress

http://dx.doi.org/10.2147/TCRM.S8775 | (c) (i) () 2015 Shalaby and Shalaby. This work is published by Dove Medical Press Limited, and licensed under Creative Commons Attribution - Non Commercial (unported, v3.0) BY NC License. The full terms of the License are available at http://creativecommons.org/licenses/by-nc/3.0/. Non-commercial uses of the work are permitted without any further
permission from Dove Medical Press Limited, provided the work is properly attributed. Permissions beyond the scope of the License are administered by Dove Medical Press Limited. Information on permission from Dove Medical Press Limited, provided the work is properly attributed. 
in predicting future cardiovascular events and target organ damage. ${ }^{6,7}$ To assess risk, whole daytime and nighttime ambulatory BP and BP load are used. The calculation of both systolic and diastolic load threshold is manually and automatically done. It is considered abnormal if BP loads are in excess of $25 \%-30 \%{ }^{8}$

$\mathrm{BP}$ will fall at night in normotensive individuals. People who undergo this normal physiological change are described as "dippers". 9 So if more than $10 \%$ of the diurnal BP values dropped nocturnally, it is considered a normal phenomenon. The non-dipping pattern is defined as a blunted decline in the person's physiological nocturnal BP drop in whom the BP remains high, ie, less than $10 \%$ lower than daytime average. ${ }^{10}$

Heart complications such as ventricular hypertrophy as well as renal insults with its events of microalbuminuria and decreased arterial acquiescence are developed in type 1 diabetic patients who display normal BP with non-dipping pattern; moreover, these patients represent a worse outcome. ${ }^{11,12}$

Surprisingly, there are relatively few data to recognize whether the changes of BP through the day are represented in patients with diabetes mellitus as in the normal population. ${ }^{13}$

It is known that approximately one third of diabetic patients will suffer from renal insult an extended time after onset of diabetes. Clinically detectable diabetic nephropathy begins with the development of microalbuminuria. ${ }^{14}$ Hypertension and microalbuminuria are considered the major cardiovascular risk factors in young patients with T1DM. Many studies have demonstrated that strict control of blood glucose level and BP significantly reduces the incidence and progression of diabetic kidney disease. ${ }^{15}$

\section{Aim of study}

The present study was undertaken to characterize type 1 diabetic children and adolescents for detection of subtle BP abnormalities using ambulatory blood pressure monitoring (ABPM) and determining its relation to microalbuminuria and other diabetic parameters.

\section{Methods and materials}

The studied groups included 40 patients with T1DM. Their ages were from 8 to 17 years. All were diagnosed by decreased level of C-peptide (connecting peptide) with symptoms of diabetes; they were followed-up in pediatric clinic of Al Ansari Specialist Hospital. The studied group included 15 males and 25 females. Exclusion criteria were as follows: hypertensive patients, age above 18 years, receiving medication that affects BP or kidney such as angiotensin-converting-enzyme (ACE) inhibitors and other antihypertensive drugs, and other chronic illness regarding heart and kidneys. Inclusion criteria of diabetic group were children and adolescents aged below 18 years, diabetic patients diagnosed by glucose level, glycated hemoglobin $\left(\mathrm{HBA}_{1 \mathrm{c}}\right)$, and C-peptide levels, normotensive by traditional simple sphygmomanometer method, and no history of medication such as antihypertensives or ACE inhibitors. Inclusion criteria of control group were children and adolescents aged below 18 years, normotensive by traditional simple sphygmomanometer method, no history of medication such as antihypertensives or ACE inhibitors, and no history of chronic illness such as diabetes, heart, or kidney diseases. The control group included 24 children (nine males, 15 females) of matched age and sex. They were randomly chosen from children attending outpatient clinics for general checkups and agreed to participate in this research. The study was approved by the local ethics committee, and informed consent was obtained from the parents or legal guardians of participating children and from children aged above 13 years.

All the studied groups were thoroughly evaluated. Full history-taking included duration of diabetes in years, dosage of insulin (units/kg of body weight) weight, height, and body mass index (BMI). Venous blood for testing $\mathrm{HBA}_{1 \mathrm{c}}$ levels was drawn from all study groups three times within at least 3 months interval, and the normal range was considered from $4.05 \%$ to $6.05 \%$ according to the Diabetes Control and Complication Trial. The test was done using COBAS INTEGRA 400 (Hoffman-La Roche Ltd., Basel, Switzerland) for the quantitative determination of percent $\mathrm{HBA}_{1 \mathrm{c}}$ following manufacturer guidelines.

The International Society for Pediatric and Adolescent Diabetology defined persistent microalbuminuria as albumin excretion rate of $20-200 \mathrm{mg} / \mathrm{min}$ in timed overnight urine collection in two consecutive urine specimens 4 weeks apart. They also considered albumin/creatinine ratio of $30-300 \mathrm{mg} / \mathrm{g}$ in the morning spot urine sample as positive for microalbuminuria. In 24 hours urine collection; it is defined positive if albumin excretion rate is $30-300 \mathrm{mg} / 24$ hours. In our study, we used albumin/creatinine ratio in the morning spot urine to study microalbuminuria in our studied groups. Microalbuminuria was determined from the collected three separate urine samples with at least 1 month interval. The patients were asked to avoid physical activity and had to be afebrile on the day of urine testing. Urinary albumin excretion was measured by the nephelometric method. BP profiles were compared with albumin/creatinine ratio.

\section{Twenty-four hour ABPM}

ABPM was measured by an oscillometric monitor (Win Pro Model PG MAP; SunTech Medical Inc., Morrisville, 
NC, USA) that was validated for children. The monitor was attached to the nondominant arm using an appropriately sized cuff. The application of cuff around the arm should not be too tight or too loose; this was easily done by putting two fingers below the cuff area to ensure correct fit. The children were told that they may resume normal activities but instructed not to participate in strenuous activities or contact sports while wearing the monitor. They were asked to wear comfortable, loose shirts and a belt. The monitor was programmed to measure BP every 20 minutes during the day between 8 am and $10 \mathrm{pm}$ and every 30 minutes during anticipated night sleep time (10 pm and $8 \mathrm{am}$ ). A reminder card was given to the volunteers to record their hours of sleep and when exactly they woke up, which was valuable when analyzing their BP values. Adhering to these instructions was a cornerstone for estimation of nocturnal dipping. ${ }^{16}$ The ABPM recording was considered acceptable when a minimum of one reading per hour for a minimum of 20 hours (including six readings during sleep) was available. Mean daytime, mean nighttime, systolic BP, diastolic BP, and heart rate were calculated.

The night/day systolic BP and diastolic BP ratio was calculated for each patient and those with a ratio higher than 0.9 were classified as non-dippers. ${ }^{17}$

The nocturnal dip percentage is defined as more than $10 \%$ drop in systolic and diastolic readings and calculated as: ${ }^{18}$

$$
\frac{\text { Daytime mean BP }- \text { Nighttime mean BP }}{\text { Daytime mean BP }} \times 100
$$

Ambulatory hypertension was considered to exist when the means of total daytime or nighttime systolic or diastolic BP were higher than expected for the 95th percentile of the subject's age, sex, and height, using standardized tables. ${ }^{18}$

We used $z$-score formula for BP parameters to normalize our data using the following equation:

$$
\begin{aligned}
& z \text {-score } \\
& \text { value }
\end{aligned}=\frac{\begin{array}{r}
\text { Patient BP value }- \text { normal BP value } \\
\text { for age and sex }
\end{array}}{\text { SD of normal BP value }}
$$

In the studied groups, $\mathrm{BP} z$-score $>0$ means that systolic, diastolic, or mean BP is more than 95th percentile for sex, age, and height.

\section{Statistical analysis}

Statistical analysis was performed using $\operatorname{SPSS}^{\circledR}$ Statistics 20 (IBM Corporation, Armonk, NY, USA). After testing for Gaussian distribution (Kolmogrov-Smirnov), we found our data were nonparametric, and thus we used nonparametric test for comparisons between studied groups (Mann-Whitney). Multiple linear regression analysis was used to identify diabetes-associated risk factors for arterial hypertension. The independent variables which were used to compare with BP profiles were: age in years, total diabetes duration in years, sex, $\mathrm{HBA}_{1 \mathrm{c}}$ level, BMI, and the dosage of insulin in units/ $\mathrm{kg}$ of weight. Statistical results were presented as mean \pm standard deviation. In comparison tests, significance was defined by a $P$-value less than 0.05 and highly significant if less than 0.01 .

\section{Results}

Demographic, descriptive data including that of diabetes and BP profiles and their comparisons between patients and control groups were shown in Table 1. On comparing the data between the two sexes, we found that most of our study parameters with descriptive BP profiles did not differ between the two sexes (Table 2).

$\mathrm{HBA}_{1 \mathrm{c}}$, albumin/creatinine ratio, diabetes duration, and insulin dose were positively correlated with all BP parameters including systolic, diastolic, and mean (both nocturnal and diurnal); on the other hand, they were negatively correlated with nocturnal dipping of BP (Table 3).

Multiple regression analysis using age, sex, BMI, albumin/creatinine ratio, $\mathrm{HBA}_{1 \mathrm{c}}$, insulin dose, and diabetes duration as independent factors was performed (Table 4). It was found that systolic, diastolic, and mean arterial BP were significantly related to albumin/creatinine ratio, $\mathrm{HBA}_{1 \mathrm{c}}$ ' insulin dose, and BMI. Diabetes duration was significantly associated with increased night systolic BP.

Nocturnal dipping of BP was only associated with albumin/creatinine ratio (Table 5).

\section{Discussion}

In this study, diabetic children showed abnormal BP profiles both systolic and diastolic with significant failure of nocturnal dipping.

Age-related changes in BP regulation were observed in diabetic patients suggesting accelerated vascular ageing. ${ }^{19}$

Being a diabetic patient, one is susceptible to cardiovascular complications and this risk increases significantly if one is pre-hypertensive with changes in ambulatory BP readings; this is evidenced in the Strong Heart Study. ${ }^{20}$ Our study showed a similar conclusion as these "risky events" already began in children and adolescents who suffered from T1DM.

The increased night BP and occurrence of non-dipping is usually accompanied by cardiovascular insults in most patients.

This insult is an outcome of structural changes in arteries and their higher tone. ${ }^{21}$ Major complications such as stroke 
Table I Descriptive data and comparison study between studied groups using Mann-Whitney test

\begin{tabular}{|c|c|c|c|c|c|}
\hline \multirow[t]{2}{*}{ Parameters } & \multicolumn{2}{|c|}{$\begin{array}{l}\text { Patients } \\
(n=40)\end{array}$} & \multicolumn{2}{|c|}{$\begin{array}{l}\text { Controls } \\
(n=24)\end{array}$} & \multirow[t]{2}{*}{$P$ (significance) } \\
\hline & Mean & Standard deviation & Mean & Standard deviation & \\
\hline Age in years & 11.56 & 2.82 & 13.5 & 2.96 & 0.067 \\
\hline Height z-score & $1.4 \mid$ & 12.92 & 1.54 & 14.37 & 0.014 \\
\hline BMI & 19.40 & 3.04 & 19.36 & 1.97 & 0.761 \\
\hline IDDM duration in years & 4.64 & 2.70 & 0.0 & 0.0 & $<0.000 \mathrm{I}$ \\
\hline $\mathrm{HBA}_{\mathrm{lc}}$ & 11.22 & 1.70 & 5.00 & 0.0 & $<0.000 \mathrm{I}$ \\
\hline Insulin dose units/kg BW & 0.99 & 0.27 & 0.0 & 0.0 & $<0.0001$ \\
\hline Albumin/creatinine ratio & 42.34 & 8.673 & 16.83 & 3.12 & $<0.000 \mathrm{I}$ \\
\hline $\begin{array}{l}\text { Daytime systolic blood } \\
\text { pressure } z \text {-score }\end{array}$ & 7.73 & 1.62 & 0.0 & 0.0 & $<0.0001$ \\
\hline $\begin{array}{l}\text { Nighttime systolic blood } \\
\text { pressure z-score }\end{array}$ & 8.73 & 0.78 & 0.0 & 0.0 & $<0.000$ I \\
\hline $\begin{array}{l}\text { Daytime diastolic blood } \\
\text { pressure z-score }\end{array}$ & 5.80 & 0.38 & 0.0 & 0.0 & $<0.000$ I \\
\hline $\begin{array}{l}\text { Nighttime diastolic blood } \\
\text { pressure } z \text {-score }\end{array}$ & 9.50 & 1.95 & 0.0 & 0.0 & $<0.000$ I \\
\hline $\begin{array}{l}\text { Mean daytime blood } \\
\text { pressure } z \text {-score }\end{array}$ & 5.22 & 0.79 & 0.0 & 0.0 & $<0.000$ I \\
\hline $\begin{array}{l}\text { Mean nighttime blood } \\
\text { pressure z-score }\end{array}$ & 6.98 & 0.67 & 0.0 & 0.0 & $<0.0001$ \\
\hline Nocturnal systolic dipping & 7.80 & 4.85 & 16.12 & 3.00 & $<0.000$ I \\
\hline Nocturnal diastolic dipping & 7.68 & 4.91 & 22.46 & 3.17 & $<0.0001$ \\
\hline
\end{tabular}

Abbreviations: BMI, body mass index; IDDM, insulin dependent diabetes mellitus; HBA ${ }_{1 c}$, glycated hemoglobin; BW, body weight.

and infarction of the heart easily occur in non-dippers if compared with normal dippers. ${ }^{22}$

The studied diabetic children and adolescents had abnormal BP regulation, especially during nighttime which means they may be facing many vascular complications even if they were only recently diagnosed as diabetics. The results

Table 2 Comparison study between males and females in the study group by Mann-Whitney test

\begin{tabular}{ll}
\hline Parameters & $\mathbf{P}$ (significance) \\
\hline Age & 0.308 \\
Height & 0.199 \\
BMI & 0.685 \\
IDDM duration in years & 0.845 \\
HBA $_{\text {Ic }}$ & 0.408 \\
Insulin dose units/kg BW & 0.775 \\
Albumin/creatinine ratio & 0.685 \\
Daytime systolic blood pressure z-score & 0.663 \\
Nighttime systolic blood pressure z-score & 0.822 \\
Daytime diastolic blood pressure z-score & 0.822 \\
Nighttime diastolic blood pressure z-score & 0.663 \\
Mean daytime blood pressure z-score & 0.641 \\
Mean nighttime blood pressure z-score & 0.641 \\
Nocturnal systolic dipping & 0.916 \\
Nocturnal diastolic dipping & 0.443 \\
\hline
\end{tabular}

Abbreviations: BMI, body mass index; IDDM, insulin dependent diabetes mellitus; $\mathrm{HBA}_{\mathrm{Ic}}$, glycated hemoglobin; BW, body weight. regarding diabetic non-dipping during the night corresponds with results of Hermada et al. ${ }^{23}$

Markuszeuski et al studied the BP changes during 24 hours in T1DM patients. They demonstrated that both nocturnal systolic and diastolic BP were higher in diabetic patients than controls, and the absence of BP drop (nondippers) was more prevalent in the diabetic group. ${ }^{24}$ Their result corresponds with this study but disagree with regard to daytime BP, both systolic and diastolic. They found that daytime BP was not significantly different from the control group while this study's results demonstrated highly significant differences between both groups with regard to daytime systolic and diastolic BPs.

In this study, it was found that BMI was positively correlated with systolic BP both diurnal and nocturnal but had no effect on BP dipping. This result corresponded with that of Axel et al's findings. ${ }^{25}$ Also, some researchers demonstrated a significant association between systolic $\mathrm{BP}$ and BMI. ${ }^{18}$

The insulin need is usually increased due to insulin resistance which occurs in obese subjects with a high BMI. ${ }^{26}$ Uncontrolled diabetic condition for an extended period of time eventually causes vascular disturbances and endothelial damage that can easily lead to changes in BP values and difficulty in its regulation. ${ }^{27}$ 


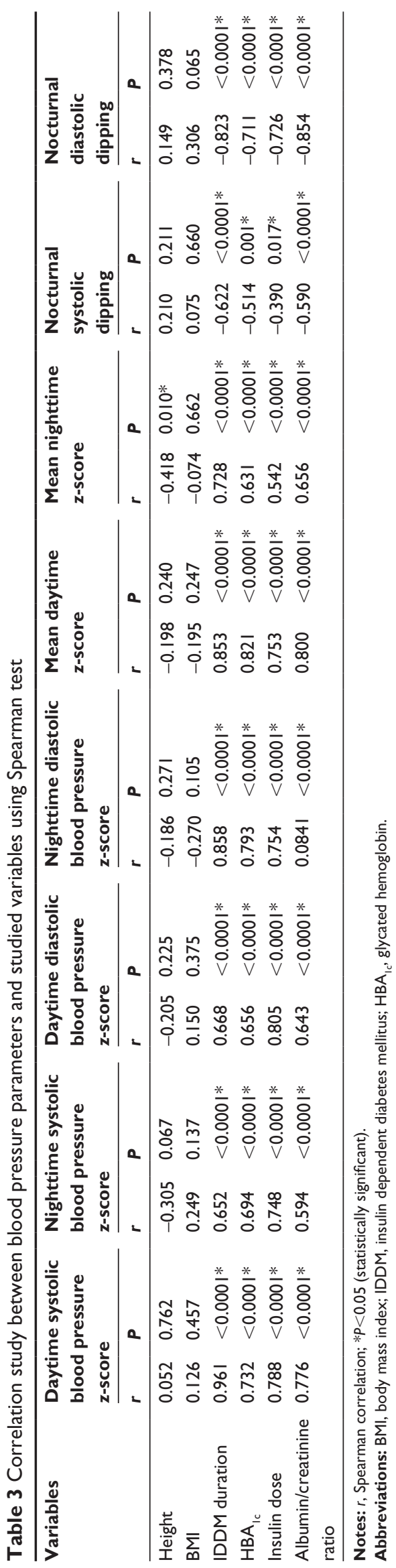

These findings support this research result that poor glycemic control reflected by elevated $\mathrm{HBA}_{1 \mathrm{c}}$ was significantly associated with elevated systolic and diastolic BP both diurnal and nocturnal. In contrast, some research failed to find any correlation between $\mathrm{HBA}_{1 \mathrm{c}}$ and hypertension in diabetic children. ${ }^{15}$

No relation between sex and alterations of BP was demonstrated, unlike Axel et $\mathrm{a}^{25}$ who found that BP changes are more prevalent in female patients and explained their findings by the fact that females tend to be obese during puberty with subsequent increase of insulin resistance, thus causing such alterations.

Our research results could be explained by the fact that both groups of males and females in study groups were not different with regard to BMI and $\mathrm{HBA}_{1 \mathrm{c}}$, so the effect of hyperinsulinemia and hyperglycemia did not appear obviously between the studied patients (both females and males), and may be due to the small sample size of this study.

Many studies showed that diabetic children mostly have diabetic renal insult which occurred due to microalbuminuria as a result of both impaired nighttime BP and uncontrolled diabetic condition. ${ }^{12,28}$ In accordance, this study data suggested that all BP profiles whether systolic or diastolic both nocturnal and diurnal were highly positively correlated with microalbuminuria. Moreover, microalbuminuria was more frequently linked to non-dippers than dippers in the diabetic group. Many investigators also revealed that diabetic children with hypertension were significantly associated with microalbuminuria. ${ }^{29,30}$ This relation is denied by other researchers who stated that there was no correlation between hypertension and microalbuminuria in diabetic children. ${ }^{15}$ It is speculated that in diabetic patients, the tone of sympathetic nervous system is increased including renal vessels and consequently resulting in diminishing both glomerular filtration rate and sodium excretion, causing albuminuria and progressive renal damage. Thus, non-dipping phenomenon resulting from higher sympathetic tone is connected to diabetic nephropathy. ${ }^{31}$

Age and diabetes duration were also correlated to changes in BP. They are non-modifiable risk factors and they can be used as a tool to classify patients at a higher risk for arterial hypertension who require special monitoring. On the other hand, metabolic state, BMI, and insulin dose are considered modifiable risk factors that need to be optimized for effective BP control during the day.

\section{Recommendations}

1) The rapid proper diagnosis of hypertension in diabetic children using ABPM is often a "wake-up call", and 
Table 4 Multiple linear regression analysis for blood pressure parameters

\begin{tabular}{|c|c|c|c|c|c|c|}
\hline \multirow[t]{2}{*}{ Parameters } & \multicolumn{2}{|l|}{ SBP } & \multicolumn{2}{|l|}{ DBP } & \multicolumn{2}{|l|}{ MAP } \\
\hline & $\mathbf{T}$ & $\boldsymbol{P}$ & $\mathbf{T}$ & $\boldsymbol{P}$ & $\mathbf{T}$ & $P$ \\
\hline \multicolumn{7}{|l|}{ Day } \\
\hline Age & -2.129 & $0.042 *$ & -1.557 & 0.131 & -4.118 & $<0.000 I^{*}$ \\
\hline Sex & 0.067 & 0.947 & 1.595 & 0.122 & 0.817 & 0.421 \\
\hline IDDM duration in years & 1.956 & 0.061 & -3.325 & $0.002 *$ & 0.642 & 0.526 \\
\hline $\mathrm{HBA}_{\mathrm{Ic}}$ & 2.231 & $0.034 *$ & 2.148 & $0.041 *$ & 2.302 & $0.029 *$ \\
\hline Insulin dose & 5.444 & $<0.000 I^{*}$ & 5.149 & $<0.000 I^{*}$ & 2.700 & $0.012^{*}$ \\
\hline BMI & 3.193 & $0.003^{*}$ & 2.977 & $0.006 *$ & 2.271 & $0.03 I^{*}$ \\
\hline Albumin/creatinine ratio & 3.950 & $<0.000 I^{*}$ & 2.993 & $0.006 *$ & 2.810 & $0.009 *$ \\
\hline \multicolumn{7}{|l|}{ Night } \\
\hline Age & -4.050 & $<0.000$ I* & -2.407 & $0.023^{*}$ & -1.895 & 0.069 \\
\hline Sex & 0.897 & 0.378 & 0.828 & 0.414 & 1.891 & 0.069 \\
\hline IDDM duration & -3.399 & $0.002 *$ & 0.920 & 0.366 & -1.544 & 0.134 \\
\hline $\mathrm{HBA}_{\mathrm{Ic}}$ & 2.886 & $0.007^{*}$ & 2.225 & $0.034 *$ & 1.609 & 0.119 \\
\hline Insulin dose & 6.048 & $<0.000 I^{*}$ & 2.473 & $0.020 *$ & 2.734 & $0.011 *$ \\
\hline BMI & 5.016 & $<0.000 I^{*}$ & -0.984 & 0.333 & 1.960 & 0.060 \\
\hline Albumin/creatinine ratio & 2.898 & $0.007^{*}$ & 2.836 & $0.008^{*}$ & 2.624 & $0.014 *$ \\
\hline
\end{tabular}

Note: $* P<0.05$ (statistically significant).

Abbreviations: BMI, body mass index; IDDM, insulin dependent diabetes mellitus; HBA $\mathrm{HC}_{\mathrm{c}}$ glycated hemoglobin; SBP, systolic blood pressure; DBP, diastolic blood pressure; MAP, mean arterial pressure.

Table 5 Multiple linear regression analysis for nocturnal dipping

\begin{tabular}{|c|c|c|c|c|c|c|}
\hline \multirow[t]{2}{*}{ Parameters } & \multicolumn{2}{|c|}{ Systolic blood pressure } & \multicolumn{2}{|c|}{ Diastolic blood pressure } & \multicolumn{2}{|c|}{ Mean blood pressure } \\
\hline & $\mathbf{T}$ & $P$ & $\mathbf{T}$ & $P$ & $\mathbf{T}$ & $P$ \\
\hline Age & -1.560 & 0.130 & 0.844 & 0.406 & 0.046 & 0.0963 \\
\hline Sex & 0.880 & 0.372 & -0.356 & 0.725 & 0.031 & 0.975 \\
\hline IDDM duration & 1.966 & 0.07 & 1.141 & 0.264 & -1.108 & 0.277 \\
\hline $\mathrm{HBA}_{\mathrm{Ic}}$ & 1.611 & 0.120 & -0.917 & 0.367 & -1.216 & 0.234 \\
\hline Insulin dose & 0.830 & 0.416 & 0.891 & 0.380 & 0.606 & 0.549 \\
\hline BMI & 0.067 & 0.947 & 1.209 & 0.237 & 1.560 & 0.130 \\
\hline $\begin{array}{l}\text { Albumin/creatinine } \\
\text { ratio }\end{array}$ & 2.897 & $0.007^{*}$ & 2.303 & $0.029 *$ & 2.989 & $0.005^{*}$ \\
\hline
\end{tabular}

Note: $* P<0.05$ (statistically significant).

Abbreviations: BMI, body mass index; IDDM, insulin dependent diabetes mellitus; $\mathrm{HBA}_{\mathrm{Ic}}$, glycated hemoglobin.

following-up those patients is an opportunity to make lifelong changes that will likely decrease their risk of developing chronic complications and enable vascular directed preventive intervention at the earliest possible time.

2) Further work is required to see if the BP load could be one of the predictive parameters in ABPM in normotensive T1DM children. While using 24-hour ambulatory BP in this study, systolic BP load had been observed to be higher than $40 \%$ in most of the diabetic patients which is considered, in hypertensive adult patients, an early prognostic marker for cardiovascular events.

\section{Acknowledgments}

Many thanks to Mr Amer, the medical technician who helped a lot with regard to ABPM device fixation and calibration for proper analysis.

\section{Disclosure}

The authors report no conflict of interest in this work.

\section{References}

1. Cuspidi C, Lonati L, Sampieri L, et al. Prevelance of target Organ damage in treated hypertensive patients: different impact of clinic and ambulatory blood pressure control. J Hypertension. 2000;18(6):803-809.

2. Ronnback M, Fagerudd J, Forsblom C, et al. Altered age-related blood pressure pattern in type 1 diabetes. Circulation. 2004;110(9): 1076-1082.

3. Lurbe E, Redon J. Ambulatory blood pressure monitoring in children and adolescents: the future. Journal of Hypertension. 2000;18(10): 1351-1354.

4. Graves JW, Althaf MM. Utility of ambulatory blood pressure monitoring in children and adolescents. Pediatric Nephrol. 2006;21(11): $1640-1652$.

5. Pellizzari M, Speiser PW, Carey DE, Fort P, Kreitzer PM, Frank GR. Twenty-Four Hour Ambulatory Blood Pressure Monitoring in Adolescents with Type 1 Diabetes: Getting Started. J Diabetes Sci Technol. 2008;2(6):1087-1093. 
6. Ritz E, Schwenger V, Zeir M, Rychlik I. Ambulatory Blood Pressure Monitoring: fancy gadgetry or clinically useful Exercise? Nephrol Dial Transplant. 2001;16(8):1550-1554.

7. Bramlage P, Deutsch C, Kruger R, et al. Validation of the custo screen 400 ambulatory blood pressure-monitoring device according to the European Society of Hypertension International Protocol revision 2010. Vasc Health Risk Manag. 2014;10:303-309.

8. Wexler R. Ambulatory blood pressure monitoring in primary care. South Med J. 2010;103(5):447-452.

9. Mahabala C, Kamath P, Bhaskaran U, Pai ND, Pai AU. Antihypertensive therapy: nocturnal dippers and nondippers. Do we treat them differently? Vasc Health Risk Manag. 2013;9:125-133.

10. Lengyl Z, Rosvill L, Nemeth C, et al. Diurnal blood pressure pattern may predict The increase of urinary albumin excretion in normotensive normoalbuminuric Type 1 diabetes mellitus patients. Diabetes Res Clin Pract. 2003;62(3):159-167.

11. Vedecchia P, Porcellati C, Schillaci G, et al. Ambulatory blood pressure. An independent predictor of prognosis in essential hypertension. Hypertension. 1994;24(6):793-780.

12. Lurbe E, Redon J, Kesani A, et al. Increase in nocturnal blood pressure and progression to microalbuminuria in type 1 diabetes. $N$ Engl J Med. 2002;347(11):797-805.

13. Bursztyn M, Ben-Dov IZ. Diabetes mellitus and 24 hour ambulatory blood pressure monitoring: broadening horizons of risk assessment. Hypertension. 2009;53(2)110-111.

14. Jacob P, Hartung R, Bohlender J, Stein G. Utility of 24 hour Ambulatory blood pressure measurement in a routine clinical setting of patients with chronic renal disease. J Hum Hypertens. 2004;18(10):745-751.

15. Basiratnia M, Abadi SF, Amirhakimi GH, Karamizadeh Z, Karamifar H. Ambulatory blood pressure monitoring in children and adolescents with type-1 diabetes mellitus and its relation to diabetic control and microalbuminuria. Saudi J Kidney Dis Transpl. 2012;23(2):311-315.

16. O’Brien E, Sheridan J, O'Malley K. Dippers and non-dippers. Lancet. 1988;2(8607):397.

17. White WB, Dey HM, Schulman P. Assessment of the daily blood pressure load as a determinant of cardiac function in patient with mild to moderate hypertension. Am Heart J. 1989;118(4):782-795.

18. Wuhl E, Witte K, Soergel M et al. Distribution of 24-h ambulatory blood pressure in children: normalized reference values and role of body dimensions. J Hypertens. 2002;20(10):1995-1200.

19. Lou LM, Gimeno JA, Gómez Sánchez R, et al [Comparison of clinical arterial pressure, home-arterial pressure measurement, and ambulatory arterial pressure monitoring in patients with type II diabetes mellitus and diabetic nephropathy]. Nefrologia. 2002;22(2):179-189. Spanish
20. Zhang Y, Lee ET, Devereux RB, et al. Prehypertension, diabetes, and cardiovascular disease risk in a population-based sample. Hypertension. 2006;47(3):410-414.

21. Scholze A, Burkert A, Mardanazai K, et al. Increased arterial vascular tone during the night in patients with essential hypertension. J Hum Hypertension. 2007;21(1):60-67.

22. Staessen JA, Thijs L, Fagard R, et al. Predicting cardiovascular risk using conventional vs ambulatory blood pressure in older patients with systolic hypertension. JAMA. 1999;282(6):539-546.

23. Hermida RC, Calvo C, Ayala DE, et al. Treatment of non-dipper hypertension with bedtime administration of valsartan. J Hypertens. 2005; 23(10):1913-1922.

24. Markuszewski L, Ruxer M, Szadkowska A, Bodalska J, Bissinger A. [Evaluation of blood pressure changes by 24 hours ambulatory blood pressure monitoring (ABPM) in young, normotensive patients with diabetes mellitus type 1]. Pol Merkur Lekarski. 2006;20(115):32-35. Polish.

25. Axel D, Christoph K, Thomas K, et al. Arterial hypertension determined by ambulatory blood pressure profiles: contribution to microalbuminuria risk in a multicenter investigation in 2,105 children and adolescents with type 1 diabetes. Diabetes Care. 2008;31(4):720-725.

26. Thorn LM, Forsblom C, Fagerudd J, et al. Metabolic syndrome in type 1 diabetes: association with diabetic nephropathy and glycemic control (the FinnDiane study). Diabetes Care. 2005;28(8):2019-2024.

27. Sorensen VR, Mathiesen ER, Clausen P, Flyvbjerg A, Feldt-Rasmussen B Impaired vascular function during short-term poor metabolic control in type 1 diabetic patients. Diabet Med. 2005;22(7):871-876.

28. Pascual JM, Rodilla E, Gonzalez C, Perez Hoyos S, Redon J. Long-term impact of systolic blood pressure and glycemia on the development of microalbuminuria in essential hypertension. Hypertension. 2005; 45(6):1125-1130.

29. Kowalewski M, Pecynska J, Glowinska B, Urban M, Urban B, Floyrs B. [The assessment of 24 hour ambulatory blood pressure monitoring (ABPM), microalbuminuria and diabetic autonomous neuropathy in children with type 1 diabetes and hypertension]. Endokrynol Diabetol Chor przemiany Materii Wieku Rowz. 2006;12(2):103-106. Polish.

30. Gallego PH, Gillbey AJ, Grant MT, et al. Early changes in 24 hour ambulatory blood pressure are associated with high normal albumin excretion rate in children with type 1 diabetes mellitus. J Pediatr Endocrinol Metab. 2005;18(9):879-885.

31. Uzu T, Ishikawa K, Fujuii T, et al. Sodium restriction shifts circadian rhythm of blood pressure from non-dipper to dipper in essential hypertension. Circulation. 1997;96(6):1859-1862.
Therapeutics and Clinical Risk Management

\section{Publish your work in this journal}

Therapeutics and Clinical Risk Management is an international, peerreviewed journal of clinical therapeutics and risk management, focusing on concise rapid reporting of clinical studies in all therapeutic areas outcomes, safety, and programs for the effective, safe, and sustained use of medicines. This journal is indexed on PubMed Central, CAS,

\section{Dovepress}

EMBase, Scopus and the Elsevier Bibliographic databases. The manuscript management system is completely online and includes a very quick and fair peer-review system, which is all easy to use. Visit http://www.dovepress.com/testimonials.php to read real quotes from published authors. 